\title{
Branchial dysplasia, mental deficiency, club feet, and inguinal herniae: a report of two further cases associated with paucity of interlobular bile ducts
}

\author{
J C Lambert, M C Saint-Paul, F Bastiani, V Paquis, A M Saunieres
}

\begin{abstract}
The observation of two new cases in a previously reported family has brought about a change in the delineation of the syndrome initially defined. To the abnormalities already described (branchial dysplasia, mental deficiency, club feet, inguinal herniae) must be added a paucity of interlobular bile ducts; the relationship between this new syndrome and the Alagille syndrome requires reconsideration.
\end{abstract}

In a previous paper we reported an unusual syndrome in a boy and his sister with branchial dysplasia, mental deficiency, club feet, and inguinal herniae. ${ }^{1}$ The observation of two new cases in the same family and the occurrence of cholestasis in the affected children has led us to change the delineation of the syndrome.

\section{Case reports}

The four children are sibs. The previously described observations are summarised below.

\section{CASE 1}

This boy had facial anomalies (malar hypoplasia, macrostomia, preauricular tags), hypospadias, reducible club feet, bilateral inguinal herniae, and

Unité de Génétique Médicale, Hôpital de Cimiez, 4 Avenue Reine Victoria, 06000 Nice, France.

J C Lambert, V Paquis, A M Saunieres

Laboratoire d'Anatomie Pathologique, Hôpital Pasteur, Nice, France.

M C Saint-Paul

Service de Pédiatrie, Hôpital de Cimiez, Nice, France. F Bastiani

Correspondence to Professor Lambert.

Received for publication 1 June 1989.

Revised version accepted for publication 19 October 1989. mental deficiency $(I Q=58)$. Skeletal $x$ ray, hearing, and chromosomal analysis were normal. The child was lost to follow up and died at the age of $2 \frac{1}{2}$ years of unknown cause but with no sign of jaundice.

\section{CASE 2}

This sister of case 1 , born $101 / 2$ months later, showed unilateral ear atresia with bilateral meatal atresia, bilateral preauricular fistula and appendage, malar hypoplasia, macrostomia, unilateral inguinal hernia, ciub feet, and ventricular septal defect. The occurrence and duration of cholestasis led to exploratory surgery of the bile ducts which proved to be normal. Histologically the diagnosis of giant cell hepatitis was proposed. After a period of improvement the child's condition deteriorated with periods of remission. No motor development was noted. $X$ ray of the spine, urinary tract exploration, and karyotype were normal.

Death occurred at 26 months. Pathological examination of the liver, revised later after the further cases, showed in two thirds of the portal fissures a lack of interlobular bile ducts with bile duct proliferation in the periphery and some inflammatory infiltrates. The plasmodial transformation of hepatocytes seen previously was thought to be only a secondary reactive change.

\section{CASE 3}

This boy, born four years after the previous child, weighed $3600 \mathrm{~g}$ at birth. At 1 month jaundice appeared and death occurred at 8 months. He was not examined personally, but no malformations were noted. The facial features were not described. The liver biopsy showed a plasmodial transformation of the whole liver parenchyma with the beginnings of some fibrotic changes. Paucity of interlobular bile ducts was noted in most of the portal fissures examined.

CASE 4

This boy was born after an interval of 3 years, after an uncomplicated pregnancy and normal delivery, birth 

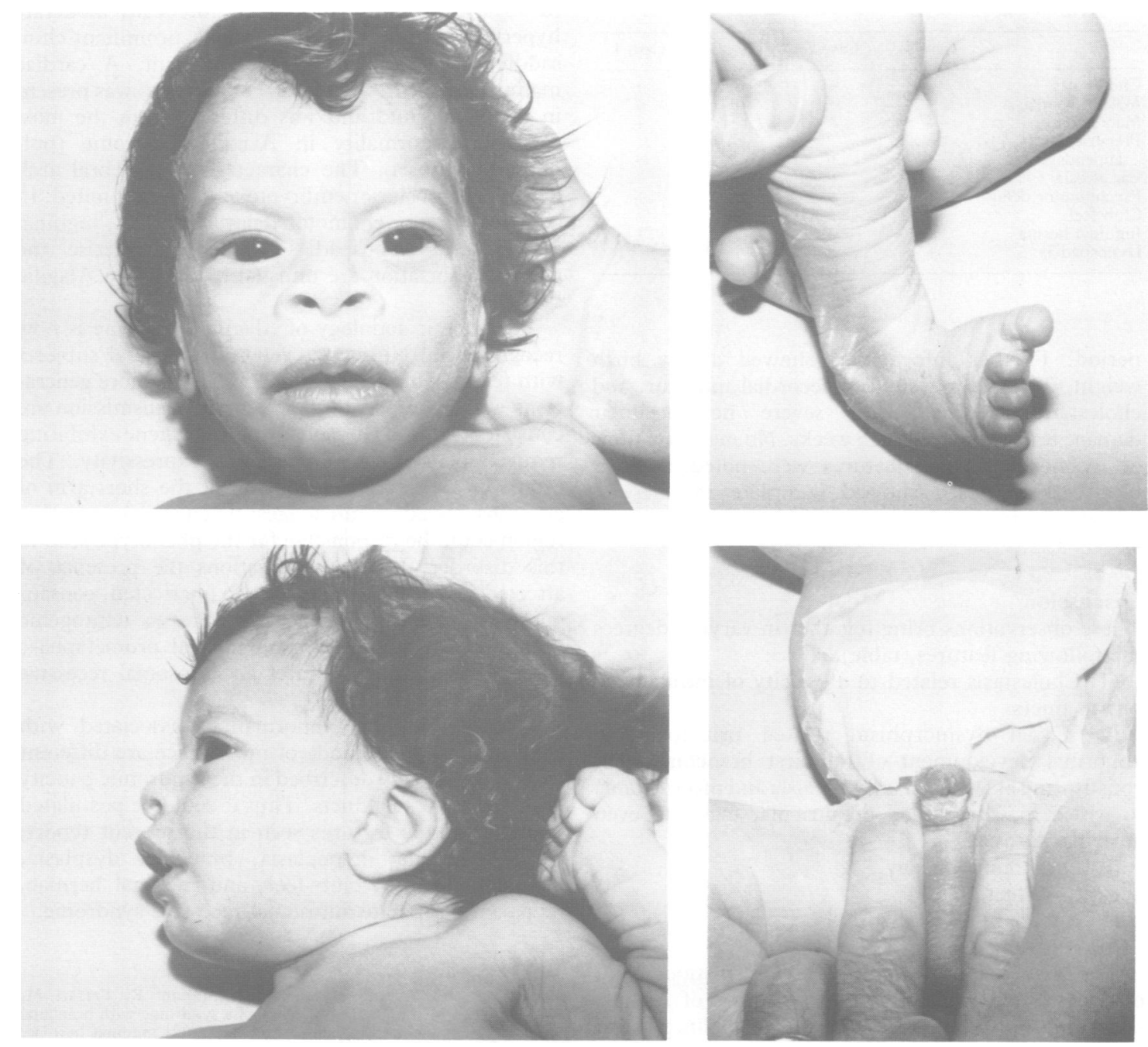

Case 3.

weight 2700 g. Clinical findings at birth showed macrostomia and malar hypoplasia, large fontanelles, club feet, hypospadias (figure), and right inguinal hernia. The skeletal $x$ rays and ophthalmological examination were normal. Vermis agenesis was discovered on cerebral ultrasonography.

At 5 days, jaundice with cholestasis appeared. At 8 weeks, a left inguinal hernia was noted. At 9 weeks, a liver biopsy was performed because of persisting jaundice. Histological examination showed a lack of bile ducts in some portal fissures which were often oedematous with inflammatory changes. A plasmodial transformation was noted. At 6 months, jaundice was still persistent with periods of remission. Growth and mental development were very poor. There was marked axial hypotonia. $X$ ray and ophthalmological examination remained normal. The karyotype performed with high resolution banding was normal.

The parents are first cousins. The mother was 22 years old at the first child's birth and there was no history of drug or radiation exposure or illness during the four pregnancies. The father was 28 years old at the first child's birth. Nine years previously he had undergone six months' treatment for tubercular pleurisy. By questioning the parents we learnt that a distant cousin (consanguinity with reported cases = $1 / 128$ ) had died from jaundice during the neonatal 
Clinical findings in the four children.

\begin{tabular}{|c|c|c|c|c|}
\hline & Case 1 & Case 2 & Case 3 & Case 4 \\
\hline Cholestasis & - & + & + & + \\
\hline Malar hypoplasia & + & + & $?$ & + \\
\hline Macrostomia & + & + & ? & + \\
\hline \multicolumn{5}{|l|}{ Preauricular } \\
\hline appendages & + & + & $?$ & - \\
\hline Ear atresia & - & + & ? & - \\
\hline Psychomotor delay & + & + & ; & + \\
\hline Club feet & + & + & ? & + \\
\hline Inguinal hernia & + & + & ; & + \\
\hline Hypospadias & + & 1 & ? & + \\
\hline
\end{tabular}

period. Further information showed a low birth weight $(2310 \mathrm{~g})$, a systolic praecordial murmur, and cholestatic jaundice with severe hepatocellular damage leading to death at 5 weeks. No malformations or dysmorphic facial features were noted. A liver biopsy after death showed complete intrahepatic biliary atresia.

\section{Discussion}

These observations bring together in varying degrees the following features (table).

(1) Cholestasis related to a paucity of intrahepatic biliary ducts.

(2) Facial dysmorphism related principally to abnormal development of the first branchial arch, constituting at least malar hypoplasia and macrostomia to which may be added preauricular tags and even auricular atresia.

(3) Psychomotor delay.

(4) Club feet.

(5) Inguinal herniae.

(6) Hypospadias.

The association of multiple malformations with ductular hypoplasia raises the possibility of Alagille syndrome (arteriohepatic dysplasia). ${ }^{2}$ Clinical and pathological expression of the cholestasis in the present cases argues in favour of this syndrome. The relative paucity of intrahepatic bile ducts is not always obvious at the first examination. The lack of jaundice in the first child is consistent with the diagnosis since cholestasis is not a constant feature in Alagille syndrome. Only the severity of hepatic damage seems more pronounced in our observations.

However, the other major signs of the syndrome ${ }^{34}$ were not present. The characteristic features present in $95 \%$ of patients (prominent forehead, moderate hypertelorism, deep set eyes, small, prominent chin, saddle or straight nose) are different. A cardiac malformation (present in $85 \%$ of patients) was present in only one child and was different from the most frequent abnormality in Alagille syndrome (pulmonary stenosis). The characteristic vertebral arch defects and posterior embryotoxon were not noted. In addition, the psychomotor delay, club feet, inguinal hernia, and hypospadias which characterise the present association are unusual or absent in Alagille syndrome.

The genetic aetiology of Alagille syndrome is now recognised. ${ }^{34}$ Numerous reports of several subjects with features of the syndrome in two or more generations with examples of male to male transmission are consistent with an autosomal dominant gene exhibiting reduced penetrance and variable expressivity. The report of a case with a deletion of the short arm of chromosome $20^{5}$ might suggest that a mutation in that region could be responsible for the phenotype seen in this disorder. In our observations the presence of affected sibs of both sexes born to unaffected, consanguineous parents with no exposure to teratogenic agents during pregnancy and normal prometaphase cytogenetic studies indicates an autosomal recessive mode of inheritance.

To conclude, the abnormalities associated with cholestasis and the mode of inheritance are different from those usually described in the syndromic paucity of interlobular bile ducts. Thus it could be postulated that the unique features seen in the present report, namely ductular hypoplasia, branchial dysplasia, mental deficiency, club feet, and inguinal herniae, represent a separate autosomal recessive syndrome.

1 Lambert JC, Ayraud N, Martin J, Mariani R, Ferrari M, Donzeau M. Familial occurrence of a syndrome with branchia dysplasia, mental deficiency, club feet, and inguinal herniae. f Med Genet 1982;19:214-5.

2 Alagille D, Odievre M, Gautier M, Dommergues JP. Hepatic ductular hypoplasia associated with characteristic facies, vertebral malformations, retarded physical, mental and sexual development, and cardiac murmur. F Pediatr 1975;86:63-71.

3 Alagille D, Estrada A,Hadchouel $M$, Gautier $M$, Odievre $M$, Dommergues JP. Syndromic paucity of interlobular bile ducts (Alagille syndrome or arteriohepatic dysplasia): review of 80 cases. 7 Pediatr 1987;110:195-200.

4 Mueller RF. The Alagille syndrome (arteriohepatic dysplasia). $f$ Med Genet 1987;24:621-6.

5 Byrne JLB, Harrod MJE, Friedman JM, Howard-Peebles PN. $\operatorname{Del}(20 p)$ with manifestations of arteriohepatic dysplasia. Am $\mathcal{J}$ Med Genet 1986;24:673-8. 